ОЧИСТКА СТОЧНЫХ ВОД ГАЛЬВАНИЧЕСКИХ ЦЕЕОВ ОТ ИОНОВ МЕДИ МОДИФИЦИРОВАННЫМ КАРБОНАТНЫМ ШЛАМОМ*

\author{
М.А. Николаева, М.Н. Котмяр \\ E-mail: larisanik16@mail.ru \\ ФГБОУ ВО «Казанский государственный энергетический университет», \\ 2. Казань, Россия
}

АННОТАЦИЯ: ПреАставлена технология получения гранулированного сорбционного материала на основе шлама химводоподготовки. ААсорбция изучена в статических и Аинамических условиях. Эффективность аАсорбции по ионам меАи 90,5 \%. Построены изотерма аАсорбции и кривая аАсорбции в Аинамических условиях катионов меАи гранулированным материалом. В ходе эксперимента опреАелена Аинамическая обменная емкость, полная обменная емкость гранулированного материала. Определены показатели качества фимьтрата при пропуске воды через загрузки сорбционного материала, соответствующие ПАК веществ в воде водных объектов хозяйственно-питьевого и культурно-бытового водопотребления.

Проведено биотестирование воАной вытяжки гранукированного сорбционного материала на острую метальную токсичность Аля рыб Poecilia Reticulate Peters и ракообразных Daphnia Magna. Полученные результаты подтвержАают, что гранулированный сорбционный материал практически не опасен и не привносит вторичного загрязнения в сточные воды. ПреАставлена технологическая схема ионообменной очистки сточных вод гальванических цехов.

КАЮЧЕВЫЕ С ОВА: очистка сточных воА, гаАьваническое произвоАство, гранулированный сорбционный материал, ионы тяжелых металмов.

В машиностроительном производстве основными виАами сточных воА являются стоки гальванических цехов и травицьных отделений. Гальваническое производство является оАним из наиболее опасных источников загрязнения поверхностных вод из-за образования большого объема высокотоксичных сточных воА. Со сточной водой в водоемы попаАают ионы тяжецых метац ов (ИТМ), явцяющиеся яАами кумукятивного, канцерогенного и мутагенного Аействия. В сточных водах гамьванических цехов эти ионы присутствуют в значительных концентрациях и размичных формах,

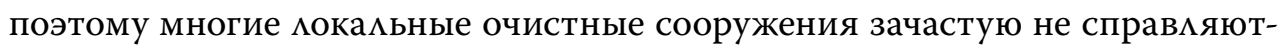

* Работа выполнена в рамках базовой части государственного задания в сфере научной Аеятельности (№ 13.6384.2017/БЧ)

(с) Николаева А.А., Котцяр М.Н., 2019

Научно-практический журнал № 5, 2019 г. 
ся со своей задачей, а концентрация ИТМ на выходе превышает установленные нормы предельно Аопустимого сброса (ПАС) [1].

Сточные воды гальванических цехов и травимьных отделений могут быть концентрированными (отработанные растворы и электролиты) и разбавленными (промывные воды после разАичных технологических опера-

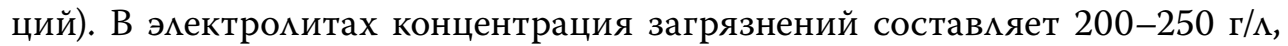
в промывных водах 100-200 мг/Ам ${ }^{3}$ [2]. Сточные воды содержат кислоты, щелочи и соми метам ов [3].

Существующие реагентные, биологические, электрохимические метоАы очистки сточных вод не всегАа позволяют производить снижение концентрации Ао норм ПАС, поэтому применение аАсорбционных технологий, основанных на использовании отходов производства в качестве сорбционных материалов, на ступенях доочистки является актуа ьным и перспективным направлением. Простота аппаратурного оформ ения, глубокая степень извлечения, экономическая целесообразность способствуют применению аАсорбционного метода очистки сточных воА от ИТМ в промышленных масштабах. Промышленно выпускаемые сорбенты характеризуются высокой стоимостью. Разработка Аля очистки сточных вод относительно неАорогих сорбционных материалов, получаемых из отходов производства, имеет практическое значение. В работе рассмотрена возможность использования многотоннажного отхода энергетики в качестве сорбционного материала при очистке сточных воА промышленных преАприятий от ионов меАИ.

\section{РЕЗУАЬТАТЫ ИССАЕАОВАНИЯ И ОБСУЖАЕНИЕ}

Многотоннажный отход энергетики - шлам химводоподготовки (ХВП), образующийся на стаАии преАварительной очистки сырой воды при провеАении известкования и коагуляции. В зависимости от объемов производства электрической и тепмовой энергии на объектах теплоэнергетики ежегодно образуется от 6,5 до 7 тыс. т шлама. Шиам удацяется из аппаратов осветлителей в виАе пульпы с влажностью 90 \%, которая направляется на шламоотвалы Аля обезвоживания.

Экспериментальные исследования проведены с использованием шлама химводоподготовки Казанской ТЭЦ-1. Выполнен рентгенографический качественный фазовый анализ шлама на Аифрактометре D8 Advance фирмы Bruker, который показал следующий состав: кацьцит $\mathrm{CaCO}_{3}-70 \%$, брусит $\mathrm{Mg}(\mathrm{OH})_{2}-9 \%$, порт аанаит $\mathrm{Ca}(\mathrm{OH})_{2}<1 \%$, кварц $\mathrm{SiO}_{2}-0,5$ \%, прочие вещества - 17,5 \% [4,5]. Анализ шлама методом газовой хроматомасс-спектрометрии с электронной ионизацией DFS производства «ThermoFisherSch.Cu» выявим на его поверхности типовой набор функционацьных групп гуминовых веществ: $-\mathrm{OH},=\mathrm{NH},-\mathrm{CH}_{3},=\mathrm{CH}_{2}$, ароматических $-\mathrm{CH}=\mathrm{CH}-$ связей, $-\mathrm{COOH}-$ карбоксимьных групп и $-\mathrm{OH}-$ 
спиртовых групп до 12 \% (масс). Химический состав шлама преАставлен преимущественно карбонатом камьция. Несмотря на то что в шламе соАержатся тяжемые метациы, отход относится к пятому кцассу опасности, т. е. степень вреАного возАействия материала на окружающую природную среду практически неопасна. Основные физико-химические и технологические характеристики шлама представлены в табл.1.

Таблица 1. Физико-химические и технологические характеристики шлама Table 1. Physical/chemical and technological properties of the slurry

\begin{tabular}{|c|c|c|c|c|c|}
\hline Насыпная плотность & \multicolumn{5}{|c|}{$560 \mathrm{\kappa r} / \mathrm{M}^{3}$} \\
\hline Зольность сухого шиама & \multicolumn{5}{|c|}{ 89\% (37 \% - Аля замазученного шиама) } \\
\hline Органический углерод & \multicolumn{5}{|l|}{$11 \%$} \\
\hline 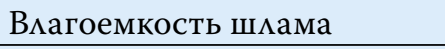 & \multicolumn{5}{|c|}{$57 \%$ масс. } \\
\hline Гранулометрический состав & $\begin{array}{c}>1,4 \\
26,9 \%\end{array}$ & $\begin{array}{r}1,0 \div 1,4 \\
5,7 \%\end{array}$ & $\begin{array}{c}0,5 \div 1,0 \\
8,7 \%\end{array}$ & $\begin{array}{c}0,09 \div 0,5 \\
49,8 \%\end{array}$ & $\begin{array}{c}<0,09 \mathrm{мм} \\
8,9 \%\end{array}$ \\
\hline $\mathrm{pH}$ & \multicolumn{5}{|c|}{ 8,53 (слабощелочная) } \\
\hline
\end{tabular}

В практике очистки сточных воА на промышленных преАприятиях от ионов тяжемых метам ов используются аАсорбционные ими ионообменные фимьтры с гранулированной загрузкой. Поэтому на основе меккодисперсного шлама разработан гранулированный сорбционный материах (ГСМ).

Аля получения гранул мелкодисперсный шлам с размером частиц от 0,01 Ао 0,09 мм смешиваци с жиАким натриевым стеклом при массовом и объемном соотношении 2:1 соответственно. Аанное соотношение подобрано экспериментацьным путем: при меньшем соотношении происходит неполное пропитывание шлама жиАким натриевым стекцом, при послеАующем обжиге гранулы осыпаются; при большем соотношении отмечен перерасход связующего. Смесь АовоАили Ао однородной массы, окатывание гранул производими вручную. Образовавшиеся гранулы выдерживали в печи при температуре $400{ }^{\circ} \mathrm{C}$ в течение 3 ч, Аалее охлажАали их до комнатной температуры в эксикаторе. В результате гранулы имеют размер 0,5-2,5 мм, характеризуются средней гидрофимьностью (влагоемкость - 15 \% масс.). Технические характеристики полученного гранукированного материала: суммарный объем пор - 0,592 см³/г, уАельная поверхность - 46,2 м²/г, насыпная плотность - 556 кг/Ам ${ }^{3}$, прочность на истирание $-78 \%$.

ААя оценки аАсорбционной способности ГСМ по отношению к катионам меди проведены исследования на модельных растворах $\mathrm{CuSO}_{4} \times 5 \mathrm{H}_{2} \mathrm{O}$ концентрацией 50 мг/Ам ${ }^{3}$. Эффективность аАсорбции по ионам меАи составика 90,5 \%. Построена изотерма аАсорбции ионов $\mathrm{Cu}^{2+}$ из водных модельных растворов ГСМ в статических условиях (рис. 1). При этом использован метод переменных навесок и постоянной концентрации.

\section{Научно-практический журнал № 5, 2019 г.}


ОАновременно в семь конических колб наливали 100 мл модельного раствора с концентрацией $\left(\mathrm{C}_{\mathrm{Cu}^{2+}}=100 \mathrm{Mг} / \mathrm{AM}^{3}\right)$, Аобав яли размичные навески ГСМ в количестве 0,01-2 г. После 24 ч перемешивания на мабораторном встряхивателе ГСМ отделяли от раствора с помощью бумажного фильтра и определяли концентрацию $\mathrm{Cu}^{2+}$ в фильтрате. Величину аАсорбционной емкости $(A$, мг/г), рассчитывали по формуке:

$$
\mathrm{A}=\frac{\mathrm{C}_{\text {исх }}-\mathrm{C}_{\mathrm{p}}}{\mathrm{m}} \times \mathrm{V},
$$

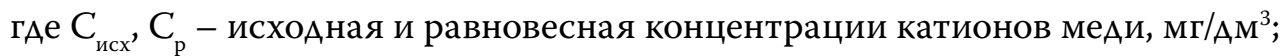
$\mathrm{V}$ - объем модемьного раствора, $\mathrm{AM}^{3} ; \mathrm{m}$ - Аоза шлама, г.

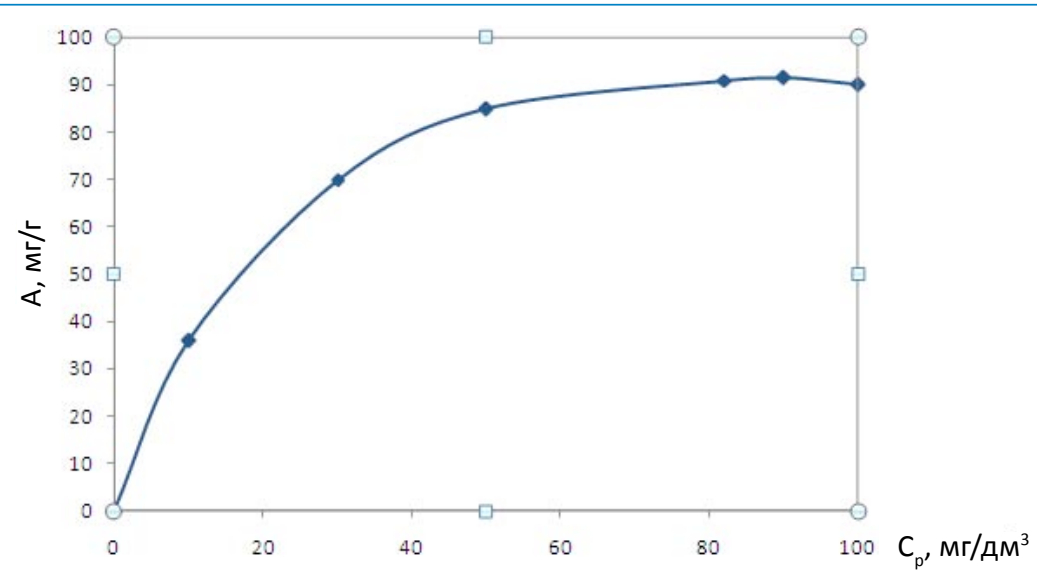

Рис. 1. Изотерма адсорбции ионов $\mathrm{Cu}^{2+}$ гранукированным сорбционным материалом.

Fig. 1. The $\mathrm{Cu}^{2+}$ sorption with a granulated sorption material isotherm.

Выпуклая форма изотермы относится к I типу по кмассификации Брунауэра, Аемина и Телмера, соответствует изотерме $\Lambda$ енгмюра L-типа.

Химический состав высушенного гранулированного шлама (влажность $3 \%$ ) представлен в основном $\mathrm{CaCO}_{3}$ и $\mathrm{MgCO}_{3}$. Катионы меди $\mathrm{Cu}^{2+}$, вступая с ними в химическую реакцию, образуют следующие труднорастворимые соединения: $\mathrm{Cu}_{2}(\mathrm{OH})_{2} \mathrm{CO}_{3}$, произведение растворимости $\Pi \mathrm{P}=1,7{ }^{\prime \prime} 10^{-34}, \mathrm{CuCO}_{3}, \Pi \mathrm{P}=$ $2,5^{\prime \prime} 10^{-10}$ (при температуре $25^{\circ} \mathrm{C}$ ). РасхоА ГСМ определяется по следующей реакции: $\mathrm{Cu}^{2+}+\mathrm{CaCO}_{3}{ }^{\prime} \mathrm{MgCO}_{3}+2 \mathrm{H}_{2} \mathrm{O} \rightarrow 2 \mathrm{Cu}(\mathrm{OH})_{2}+\mathrm{Ca}^{2+}+\mathrm{Mg}^{2+}+2 \mathrm{CO}_{2}$.

Аля производственных процессов важно изучение аАсорбции ионов тяжелых металмов в Аинамических условиях. ААсорбция в Аинамических условиях имеет большие технологические, экспцуатационные и экономические преимущества по сравнению с аАсорбцией в статических условиях, позволяя более полно использовать емкость сорбента. При использовании 
ГСМ слеАует учитывать, что очищаемая вода Аолжна иметь кислую среду, при контакте с ГСМ она нейтрализуется. Процесс адсорбции ионов меди исследован на ГСМ фракции размером 0,5-2,5 мм на кабораторной установке, преАстав яющей фильтровальную стекцянную колонку Аиаметром 25 мм. Концентрация ионов меАи в модельном растворе равна 50 мг/Ам ${ }^{3}$ и является среАней на входе в аАсорбционный фимьтр. Высота слоя загрузки 20 см, масса - 56 г, скорость фильтрации - 3,5 м/ч. Проскок ионов меАи фиксируется при концентрации 1 мг/Ам³. На рис. 2 показана кривая аАсорбции катионов меди ГСМ в Аинамических условиях.

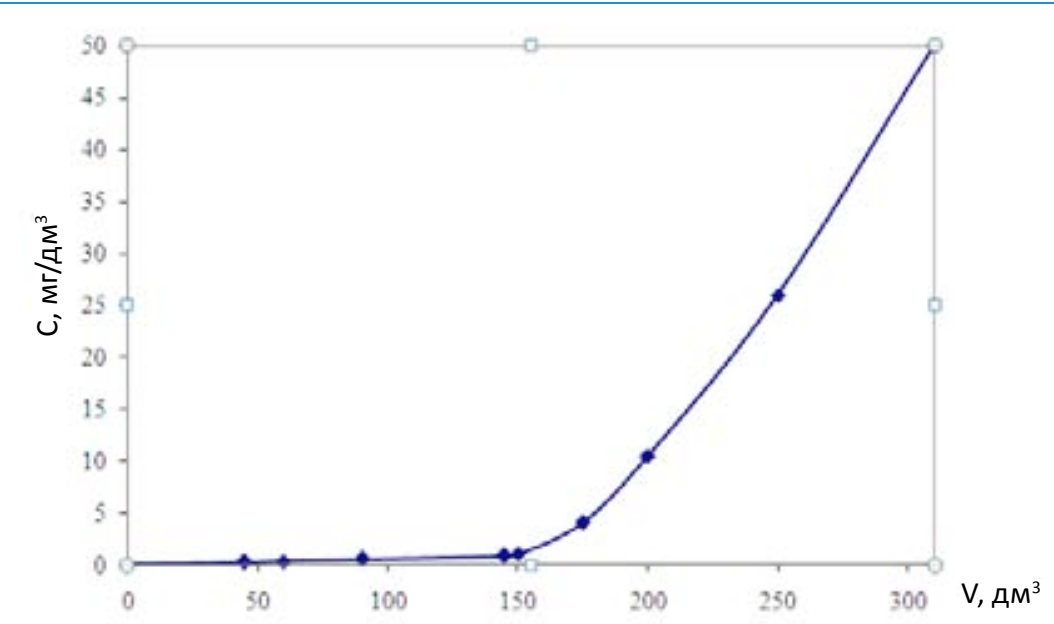

Рис. 2. Кривая аАсорбции катионов меАи ГСМ в Аинамических условиях.

Fig. 2. The GSM copper cation sorption curve in the dynamic conditions.

В ходе эксперимента определены динамическая обменная емкость (АОЕ) и полная обменная емкость (ПОЕ). Результаты эксперимента преАставлены в табл. 2.

Таблица 2. Аинамическая и полная обменные емкости ГСМ по отношению к катионам меАи

Table 2. The GSM dynamic and full exchange capacities in respect of copper cations

\begin{tabular}{c|c|c}
\hline Показатель & Значение, мг/г & Объем пропущенной воды, $\mathrm{AM}^{3}$ \\
\hline $\mathrm{AOE}$ & 133,9 & 150 \\
ПОЕ & 276,8 & 310 \\
\hline
\end{tabular}

По уравнению Шилова рассчитано время (т) и коэффициент защитного Аействия (К) слоя ГСМ: $\tau=70,5$ ч, $\mathrm{K}=382,6$ ч/м.

Фильтрат имеет нейтральное значение величины $\mathrm{pH}=6,8-7,5$. После фильтрования через гранулы ГСМ состав воды изменяется, поэтому про- 
водицся контроль воды на остаточное содержание общей жесткости и $\mathrm{pH}$. Эти показатели фильтрата Аолжны изменяться по ионному обмену функциональных групп сорбционного материала с катионами меди. Выбор метода регенерации отработанного сорбционного материала зависит от эффективности очистки от катионов меАи и технико-экономических показателей. Предусмотрена регенерация материала разбавленным раствором $\mathrm{H}_{2} \mathrm{SO}_{4}$ с нарастающей концентрацией от 0,5-2,5 \%, пропускаемым противоточно потоку очищаемой воды.

Определены показатели качества фильтрата при пропуске воды через загрузки ГСМ, соответствующие ПАК веществ в воде водных объектов хозяйственно-питьевого и культурно-бытового водопотребления (СанПин 2.1.4.10749-01) (табл. 3).

Таблица 3. Показатели качества фимьтрата при пропускании размичных объемов воды в Аинамических условиях через ГСМ

Table 3. The filtrate quality indicators in the process of different water volumes' passage through GSM in the dynamic copnditions

\begin{tabular}{|c|c|c|c|c|}
\hline $\begin{array}{c}\text { Объем пропу- } \\
\text { щенной воАы, } \\
\text { AM }^{3}\end{array}$ & 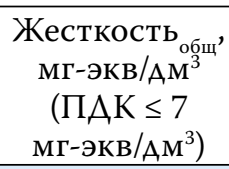 & $\begin{array}{c}\text { Щелочность } \\
\text { мГ-экв } / \mathrm{AM}^{3}\end{array}$ & $\begin{array}{c}\text { Жемезо общ' } \\
\mathrm{Mг} / \mathrm{AM}^{3} \\
(\Pi А \mathrm{~K} \leq 0,3 \\
\left.\mathrm{M \Gamma} / \mathrm{AM}^{3}\right) \\
\end{array}$ & $\begin{array}{c}\text { Кремний, } \\
\text { мг/АM } \\
(П А К \leq 10 \\
\left.\text { Мг/AM }{ }^{3}\right) \\
\end{array}$ \\
\hline Исходная вода & 2,21 & 1,51 & 0,16 & 0,31 \\
\hline 0,2 & 2,22 & 5,87 & 1,72 & 1,25 \\
\hline 0,4 & 2,22 & 4,11 & 0,92 & 1,25 \\
\hline 0,6 & 2,21 & 1,22 & 0,28 & 1,21 \\
\hline 1,0 & 2,21 & 1,11 & 0,16 & 1,21 \\
\hline 10,1 & 2,22 & 1,12 & 0,15 & 0,8 \\
\hline
\end{tabular}

Результаты, преАставленные в табл. 3, показывают, что ГСМ не привносит вторичного загрязнения в водную среАу. Следует отметить, что процесс очистки воАной среды с использованием ГСМ происходит в «мягкой», нейтральной кислой и слабощелочной среАе.

Аалее проведено биотестирование водной вытяжки ГСМ на острую цетальную токсичность Аля рыб Poecilia Reticulate Peters и ракообразных Daphnia Magna. Полученные результаты подтвержАают, что ГСМ практически неопасен и не привносит вторичного загрязнения в сточные воды.

ОАним из наиболее распространенных промышкенных методов физикохимической очистки сточной воды от ионов тяжелых металмов является аАсорбция. В результате можно осуществцять оборотное водоснабжение гальванических цехов с оАновременной утилизацией ценных компонентов. На рис. 3 преАставлена принципиальная схема установки Аля очистки сточных воА гальванического процесса [6]. 


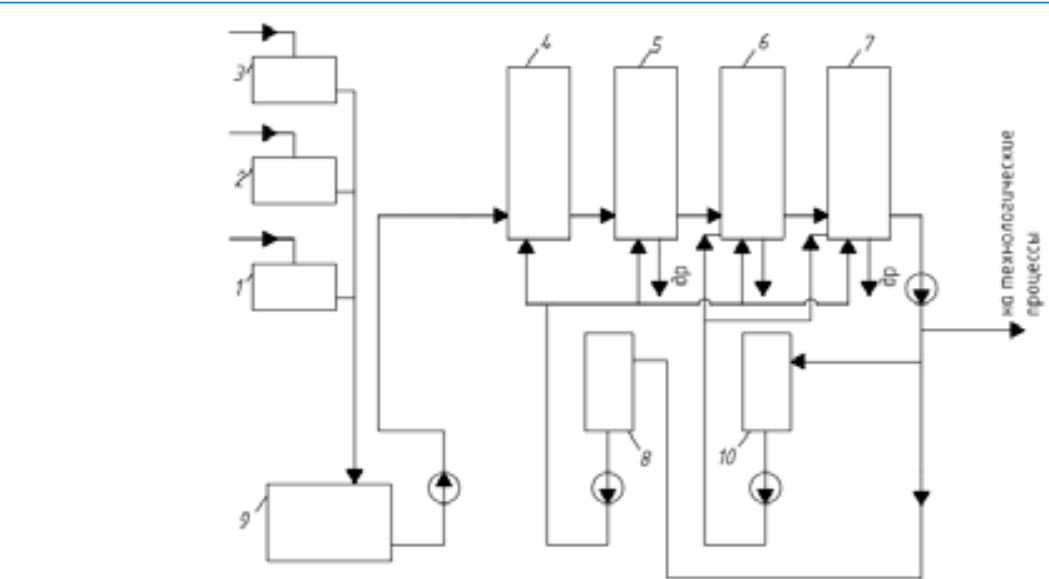

Рис. 3. Принципиальная схема установки очистки сточных воА гальванических производств: 1, 2, 3 - емкости кислых, щелочных, меАьсодержащих стоков; 5,6 - песчано-гравийный и угольный фимьтры; 6,7 - фимьтры, загруженные ГСМ; 8 - сборник чистой воды Аля промывки фильтров; 9 - усреАнитеАь, 10 - емкость регенерационного раствора.

Fig. 3. Schematic diagram of the electroplating waste waters treatment apparatus: $1,2,3$ are the tanks of acidic, alkaline and copper-containing wastes; 5,6 are sand/gravel and carbon filters; 6,7 are GSM loaded filters; 8 is a clean water collector for filters' washing;

9 is a neutralizer; 10 is a tank for a regeneration solution.

Стоки из емкостей $1,2,3$ Аля усреАнения состава и частичного отАеления механических примесей направляются в усреАнитель (9). Максимальная концентрация загрязняющих веществ - Ао 400 мг/А. При большей концентрации обязательно разбавление в усреАнителях (Аобавлением чистой воды). Из аппарата (9) стоки насосом подаются в песчано-гравильный фильтр (4) Аля очистки от механических примесей, скорость фимьтрования 5-7 м/ч. Следующая ступень - очистка активированным углем в аппарате (5) от масмопродуктов, биологических и Аругих загрязнений. Песчано-гравийный и угольный фильтры промываются очищенный водой из сборника чистой воды (8) снизу вверх. Отфильтрованная вода направляется в фильтры $(6,7)$, заполненные ГСМ. Аинейная скорость Авижения жидкости в аппаратах состав яет 10-20 м/ч. По Аостижении на выходе концентрации сорбируемых ионов $0,02-0,03$ мг-экв/Ам ${ }^{3}$ регенерацию проводят раствором серной кислоты концентрацией от 1 до $4 \%$ из емкости (10).

Опыт эксп уатации показывает, что применение Аанной технологии цемесообразно при концентрации ионов меди в сточной воде от 1,5 до 6 мгэкв/Ам ${ }^{3}$ и полном отсутствии загрязнений органического характера. Аалее часть очищенных сточных воА направ яется на технологические процессы, часть на промывку и приготовление регенерационного раствора. 


\section{ВЫВОАЫ}

В рамках проведенного исследования построены изотерма аАсорбции в статических и выходная кривая аАсорбции в Аинамических условиях катионов меАи гранулированным материалом. Определена динамическая обменная емкость ( $\mathrm{AOE}=133,9$ мг/г), полная обменная емкость гранулированного материала по отношению к катионам меАи (ПОЕ $=276,8$ мг/г). По уравнению Шияова рассчитано время т (70,5 ч) и коэффициент защитного Аействия слоя К $(382,6$ ч/м).

Показано, что ГСМ не привносит вторичного загрязнения в водной среАе, а также что водная вытяжка ГСМ не оказывает острого токсического Аействия на рыб Poecilia Reticulate Peters и ракообразных Daphnia Magna.

Представлена технологическая схема очистки сточных вод гальванического производства, которая вкмючает загруженные разработанным материалом ионообменные фимьтры. Применение аАсорбционного метода очистки позвоцяет обеспечить высокую степень очистки сточной воды и ее повторного использования Аля технологических нужА преАприятия.

\section{СПИСОК АИТЕРАТУРЫ}

1. Минлигулова Г.А., Шайхиев И.Г. Исследование очистки сточных воА, содержащих ионы тяжелых метал ов, стоками нефтехимических производств // Вестник казанского технологического университета. 2011. № 6. С. 166-171.

2. Аупейко Т.Г. Баян Е.М., Горбунов М.О. Исследование техногенного карбонатосодержащего отхода Аля очистки водных растворов от ионов никеля (II) // ЖПХ. 2004. Т. 77. № 1. C. 87-91.

3. Мур А.В., Рамамурти С. Тяжелые металмы в природных водах / пер. с англ. А. В. Гричука и Ар.; поА реА. Ю. Е. Саета. М.: Мир, 1987. 285 с.

4. Николаева А.А., Голубчиков М.А. Очистка производственных сточных вод от нефтепроАуктов модифицированными сорбционными материалами на основе карбонатного шлама //Водоснабжение и санитарная техника. 2016. №7. С. 51-58.

5. Николаева А.А., Шигабутдинова А.Ф. Ресурсосберегающая технология очистки сточных вод от ионов тяжелых металмов шиамом химводоочистки ТЭС // Энергосбережение и водоподготовка. 2013. № 4. С. 13-15.

6. Макаров В.М., Беличенко Ю.П., Галустов В.С., Чуфаровский А.И. Рациональное использование и очистка воды на машиностроительных предприятиях. М.: Машиностроение, 1988. 272 с.

Аля цитирования: Николаева А.А., Котляр М.Н., Очистка сточных вод гальванических иехов от ионов меди модибииированным карбонатным шламом// Водное хозяйство России. 2019. № 5. С.124-132.

\section{Сведения об авторах:}

Николаева Мариса Андреевна, А-р техн. наук, профессор, ФГБОУ ВО «Казанский государственный энергетический университет (КГЭУ), Россия, 420066, г. Казань, ул. Красносельская, А. 51; e-mail: larisanik16@mail.ru

Котмяр Мирослава Николаевна, канА. техн. наук, Аоцент, ФГБОУ ВО «Казанский госуАарственный энергетический университет (КГЭУ), Россия, 420066, г. Казань, ум. Красносельская, А. 51; e-mail: kotlyar-mira@mail.ru 


\title{
ELECTROPLATING PLANTS WASTEWATER TREATMENT FROM COPPER IONS WITH A MODIFIED CARBONACEOUS SLURRY
}

\section{Larisa A. Nikolaeva, Miroslava N. Kotlyar \\ Kazan State Power Engineering University, Kazan, Russia}

\begin{abstract}
The article presents a technique of the granulated sorption material production based on the chemical water treatment slurry. The sorption has been studied in statical and dynamic conditions. The sorption effectiveness by copper ions was $90.5 \%$. The isotherm of adsorption and a curve of adsorption in dynamic conditions of cations of copper has been plotted by the granulated material. During the experiment the dynamic exchange capacity, full exchange capacity of the granulated material has been determined. The filtrate quality indicators in water passage through sorption material loads in accordance with MPC of domestic drinking and recreational purposes water bodies.

The granulated sorption material extract was tested for acute lethal toxicity for Poecilia Reticulate Peters fish and Daphnia Magna Crustacea. The obtained results affirmed that the granulated sorption material was not practically hazardous and did not bring secondary pollution to wastewaters. The authors have presented a technological scheme of electroplating wastewaters ion-exchange treatment.
\end{abstract}

Keywords: wastewater, electroplating industry, granular sorption material, heavy metal ions About the authors:

Prof. Larisa A. Nikolaeva, Doctor of Technical Sciences, Kazan State Power Engineering University, ul. Krasnoselskaya, 51, Kazan, 420066, Russia; e-mail: larisanik16@mail.ru.

Miroslava N. Kotlyar, Candidate of Technical Sciences, Associate Professor, Kazan State Power Engineering University, ul. Krasnoselskaya, 51, Kazan, 420066, Russia; e-mail: kotlyarmira@mail.ru.

For citation: Nikolaeva L.A., Kotlyar M.N. Electoplating Plants' Wastewater Treatment from Copper Ions with a Modified Carbonaceous Slurry // Water Sector of Russia. 2019. No. 5. P. 124-132.

\section{REFERENCES}

1. Minligulova G.A., Shaykhiev I.G. Issledovanie ochistki stochnyh vod, soderzhashchih iony tyazhelyh metallov, stokami neftekhimicheskih proizvodstv [Studies of treatment of waste waters containing heavy metal ions with wastes of chemical/petroleumproduction] // Vestnik kazanskogo tekhnologicheskogo universiteta. 2011. №6. S. 166-171.

2. Lupeyko T.G. Bayan E.M., Gorbunov M.O. Issledovanie tekhnogennogo karbonatosoderzhashchego otkhoda dlya ochistki vodnyh rastvorov otionov nikelya (II) [Researches of a carbonatecontaining waste for water solution treatment from nickel (II) ions] // ZHPH. 2004. t. 77. № 1. S. 87-91.

3. Mur D.V., Ramamurti S. Tyazhelyemetally v prirodnyhvodah [Heavy metals in natural waters]/ Per. s angl.D. V. Grichukai dr.; Pod red.YU. E. Saeta. M.: Mir, 1987. 285 s.

4. Nikolaeva L.A., Golubchikov M.A. Ochistka proizvodstvennyh stochnyh vod ot nefteproduktov modificirovannymi sorbcionnymi materialami na osnove karbonatnogo shlama [Industrial wastewaters treatment from petroleum products with modified sorption material based on carbonaceous slurry] // Vodosnabzhenie i sanitarnaya tekhnika. 2016. № 7. S. 51-58.

5. Nikolaeva L.A., Shigabutdinova A.F. Resursosberegayushchaya tekhnologiya ochistki stochnyh vod ot ionov tyazhelyh metallov shlamom himvodoochistki TEHS [A resources-saving technique for wastewater treatment in respect of heavy metal ions with TEHS water treatment slurry] // Ehnergosberezhenie i vodopodgotovka. 2013. №4. S. 13-15.

6. Makarov V.M., Belichenko YU.P., Galustov V.S., Chufarovskij A.I. Ratsionalnoe ispolzovanie i ochistka vody na mashinostroitelnykh predpriyatiyakh [Rational use and treatment of water art machine-building plants]. M.: Mashinostroenie, 1988. 272 s. 